\title{
Hepatic Lipidosis in Two Captive Cheetahs (Acinonyx jubatus) at Kuwait Zoo
}

\author{
Mahmoud, M. A. \\ Wildlife and zoo medicine department, Faculty of veterinary medicine, \\ Suez Canal University.
}

\begin{abstract}
:
Feline hepatic lipidosis was detected in two adult male cheetahs after a prolonged state of anorexia at Kuwait zoo. Blood and tissue samples collected for bacteriological and virological examination produced negative results. Biochemical analysis was carried out on the serum extracted from the rest of the blood samples which indicated a state of hypoglycemia in animal \#1 $(51.2 \mathrm{mg} / \mathrm{dl})$ and a high level of liver enzymes (T.billi 1.7, 0.9 mg/dl, ALP 65.4, 69.2 IU/L, AST 40, 49.4 IU/L, ALT 54.3, 53.2 IU/L), TP 11.2, $9.5 \mathrm{~g} / \mathrm{dl}$ and BUN 35.2, $32.7 \mathrm{mg} / \mathrm{dl}$ in cheetah \#1 and \# 2, respectively. The blood values for CRE $(0.3,1.3 \mathrm{mg} / \mathrm{dl})$ were below normal standard values for both animals. Animal \#1 died shortly during the course of investigation and by examination of the liver it was enlarged with diffuse icteric surface and greasy texture on cut surface. There was excessive infiltration of lipid cells into hepatocytes detected by histological examination suggesting a case of hepatic lipidosis. Correction of feeding protocol for captive cheetahs by the provision of varied prey items to meet their nutritional requirements is necessary.
\end{abstract}

Key words: lipidosis, biochemical, hepatocytes, anorexia, feline, liver.

\section{Introduction}

Wild and domestic felines are prone to a number of diseases and conditions. One of the most common conditions observed in felines is hepatic lipidosis or fatty liver disease. Although the disease is idiopathic (Center, 2005), it is thought that it might result from the ways felines metabolize protein and fats (Biourge et al, 1991). The disease has also been observed in a number of other different species (James et al, 2000; Palmer and Olsen, 2002, Van saun, 2007; Barigye et al, 2007 and Gonzalez et al, 2011) and although there are differences in conditions that initiate the disease in these species, a common theme is a period of inadequate energy intake initiating body fat mobilization (Van saun, 2007). 
Cheetah, Acinonyx jubatus is one of the most endangered wild feline in the world. The species was once widely distributed from Palestine and the Arabian Peninsula to India, and throughout most of Africa (Guggisberg, 1975). As a result of poaching and habitat destruction the species disappeared from Asia, except from Iran and possibly adjacent areas, and is rare in North and West Africa (Saleh et al, 2001). Captive breeding programs for the conservation of the species are hampered by lack of genetic diversity, low fecundity, high mortality rates (O'Brien et al, 1985) and nutritional deficiencies which account for $7 \%$ of the mortality in captivity (MarkerKraus, 1997).

Due to the varieties of food items consumed by the species, in nature, the animal might not be able to derive all its food requirements in captivity with very limited food varieties. Captive cheetahs are often fed commercially prepared diets based on cats' formulas that might contribute to some of the metabolic health issues seen in captive situations (Dierenfeld et al, 2001).

The following paper underlines the possible cause of anorexia and weight loss observed in two captive cheetahs before one of them rapidly died at Kuwait zoo. Two animals, aged three years old, were kept on a staple food of chicken (one chicken of $1.25 \mathrm{~kg}$ per head per day) without any vitamins or minerals supplement since they were brought to the facility at the age of six months until symptoms developed.

\section{Materials and methods:}

\section{Animals}

Two adult male captive cheetahs were examined at Kuwait zoo based on clinical history of anorexia, loss of body weight and sudden death. The animals were confiscated by the zoo authority as part of CITES implementation program. One of the animals died during the course of investigation while the other one died seven months later as a result of feline corona virus infection.

\section{Physical examination:}

Age, gender and rectal temperature of the two animals were recorded the moment anorexia and body loss observed in both of them. All cheetahs were physically restraint by a capture net and body weights were measured using electronic scale. Skin-pinch test over the ribs was used to evaluate degree of dehydration.

\section{Collection of blood samples:}

Blood samples (15cc) were drawn from each animal using a vacutainer needle by saphenus venepuncture of the hind leg while the animals were under chemical restraint (combination of ketamine $300 \mathrm{mg} /$ $\mathrm{kg}$ and xylazine $10 \mathrm{mg} / \mathrm{kg}$ body weight) following the procedure adopted by Mussart et al. (2009). The samples were placed in sterile serum clot vacutainer tubes and later centrifuged at $3000 \mathrm{rpm}$ for 10 minutes for serum extraction. 
Samples from each animal were sent for virology examination where serum antibodies against feline panleucopenia, feline calicivirus (The Immunocomb ${ }^{\circledR}$ feline Vaccicheck Antibody test kit, Biogal) and feline infectious peritonitis ( FIP Ag test, Biotech, China) were tested using the commercial feline ELISA antibody detection test kits according to the manufacturer's instructions . A Vet Scan VS2, Abaxis, biochemical analyzer was used to estimate ten analytes in other serum samples. The serum was added to specific rotary (Comprehensive diagnostic profile) and placed in the apparatus to read asparate transminase (AST), alamine aminotransferase (ALT), alkaline phosphate (ALP), Globulin (GLOB), total bilirubin ( $\mathrm{T}$ Bili), Creatinine ( $\mathrm{CRE}$ ), blood urea nitrogen (BUN), albumin (ALB), total protein (TP) and glucose (GLU). Results for both animals were compared with the standard reference values adopted by Fagan (1980).

\section{Tissue Sampling and necropsy:}

A necropsy operation was carried out on animal \# 1, which shortly died during the course of the study. The vital organs were thoroughly inspected for macroscopic lesions or color changes. Fresh tissue samples from lungs, liver, heart, spleen and intestines were taken, sealed in sterile plastic bags and shipped to the central laboratory of public authority of agriculture and fish resources (PAAF, Kuwait) for bacteriological testing to rule out any possible bacterial infection. Histo-pathology examination was carried out on tissue samples extracted from the liver and stained with haematoxyline-eosin and Trichrome stain.

\section{Results:}

Rectal temperatures, body weights and color of mucous membranes of the animals were shown in Table 1. An average body weight loss of $22.3 \%$ was calculated based on the documented average body weight of males at that age (Marker and Dickman, 2003). Animals looked depleted with rough hair and skinny appearance. Mucous membranes of the mouth and sclera of the eye looked pale and sometimes exhibited straw coloration. Samples submitted for bacteriological and virology examinations were negative for suspected microorganisms thus ruling out any possible infection.

On post-mortem examination the dead animal \# 1 had severely enlarged, liver with diffuse icteric surface, rounded edges and greasy texture on the cut surface (Fig.1). Microscopic examination of liver tissue samples showed lipid cells infiltration within hepatic cells (Fig. 2 ). The spleen was enlarged with multifocal necrosuppurative lesions on the outer surface and the heart was congested and the stomach showed accumulation of a number of nematodes ( Ascarides spp). 
Blood analysis for biochemical analytes revealed a hypoglycaemic condition in animal \# 1 while CRE blood values were below standard normal in both animals. Blood biochemical values for AST, ALP, ALT, TP, BUN and T bili were all higher than standard normal for both animals (Table 1).

Table 1: General clinical parameters measured in the examined animals.

\begin{tabular}{|c|c|c|c|}
\hline parameter & Animal \#1 & Animal \#2 & Reference value \\
\hline Rectal temperature & $37.5 \mathrm{c}^{\circ}$ & $39 \mathrm{c}^{\circ}$ & \\
\hline Body weight & $33 \mathrm{~kg}(26.7 \%)$ & $37 \mathrm{~kg}(17.8 \%)$ & $45 \mathrm{~kg}^{1}$ \\
\hline Mucous membrane & pale & Pale & \\
\hline
\end{tabular}

${ }^{1}$ Marker and Dickman( 2003). Values in brackets are \% body weight loss.

Table 2: Serum biochemical parameters of the studied cheetahs.

\begin{tabular}{|c|c|c|c|}
\hline parameter & $\begin{array}{c}\text { Values } \\
\text { Animal \#1 }\end{array}$ & $\begin{array}{c}\text { Values } \\
\text { Animal \#2 }\end{array}$ & $\begin{array}{c}\text { Reference values } \\
\text { for cheetahs }\end{array}$ \\
\hline Glu. mg/dl & 51.2 & 62.4 & $60.8-124.2$ \\
\hline TP. g/dl & 11.2 & 9.5 & $5.7-8.0$ \\
\hline BUN mg/dl & 35.2 & 32.7 & $15.4-31.2$ \\
\hline CRE. mg/dl & 0.3 & 1.3 & $0.5-1.9$ \\
\hline T.Bili mg/dl & 1.7 & 0.9 & $0.1-0.5$ \\
\hline ALP IU/1 & 65.4 & 69.2 & $12.0-65.1$ \\
\hline AST IU/1 & 40 & 49.4 & $9.2-39.5$ \\
\hline ALT IU/1 & 54.3 & 53.2 & $8.3-52.5$ \\
GLOB mg/dl & 3.2 & 3.9 & $2.4-4.7$ \\
\hline ALB. g/l & 2.9 & 3.1 & $2.4-3.7$ \\
\hline
\end{tabular}

${ }^{1}$ Fagan, DA (1980)
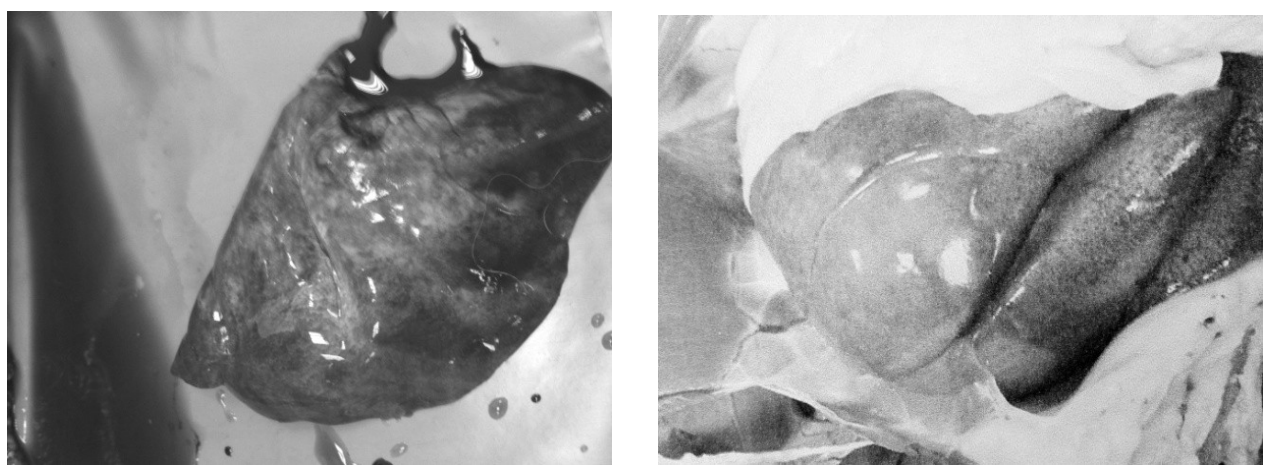

Fig 1: Enlarged liver with pale icteric coloration in animal \#1 


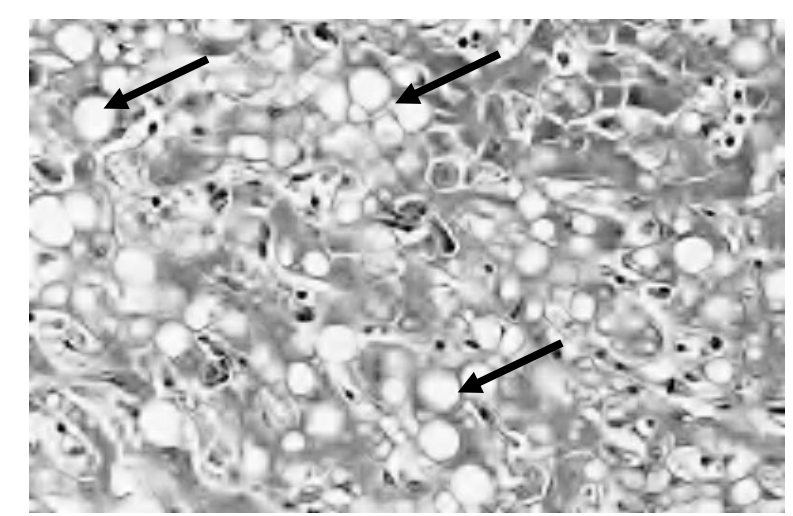

Fig 2: Hepatocytes filled with fat vacuoles in histological section

\section{Discussion:}

High serum biochemical values for ALT, ALP, AST and T.Bili with lipid cells infiltration in the hepatic cells suggests a hepatic malfunction that might be due to a condition of hepatic lipidosis in cheetah. A prolonged state of starvation that the animals might have experienced as a result of inadequate energy supply (low GLU level $51.2 \mathrm{mg} / \mathrm{dl}$ with low body weight) could have stressed the liver with overwork for fat mobilization to substitute insufficient energy supply (Cebra $\boldsymbol{e t}$ al, 1997; Marco et al, 2000). As starvation continues liver uses excess fatty acids resulted from lipolysis to supply energy (Hoeing et al, 2006). Felines are not designed to convert large stores of fat as a result of increased glycogen and lipid production, so when they are starved, the fat that is released to the liver is not processed efficiently resulting in a fatty and low functioning liver (Hoeing et al, 2007). The high measured $\mathrm{TP}$ values $(11.2 \mathrm{~g} / \mathrm{dl}$ and $9.5 \mathrm{~g} / \mathrm{dl})$ may indicate a state of depletion and dehydration in both animals as a consequence of starvation. These values of TP measured in the subjects were also higher than the average normal values $(7.7 \mathrm{~g} / \mathrm{dl})$ recorded in lynx (Lynx pardina) (Beltran et al, 2000). Roelke (1987) emphasized that poor body conditions (anemia and low body weights) of individual felines were relatively correlated to smaller prey items in the diet of these species. Smaller prey items that are encountered by felines during periods of food shortage do not provide these predators with essential food items that are capable of sustaining their energy demands. Clum et al (1996) recommended the provision of live prey with adequate size for these animals under captivity to enhance natural behavior and provide sufficient food requirements to meet body needs. Overall, whole prey with adequate size fed to captive carnivores, mainly exotic felines; provide crude protein in excess of the requirements of domestic felines 
(National research council, 1994) and higher crude fat as well which satisfy their needs (National research center, 1985). On the list of possible prey items chicken provide lower crude protein $(42.2 \%)$ and acceptable crude fat (37.8\%) when compared to other prey species such as ducks (crude protein $63.1 \%$ and crude fat $26.4 \%$ ), quails ( crude protein $71.5 \%$ and crude fat $31.9 \%$ ), voles ( crude protein $63.2 \%$ and crude fat $24.5 \%$ ), rabbits ( crude protein $63.2 \%$ and crude fat 20\%) (Dierenfeld et al, 2001). In captivity a commercially prepared raw meat or skeletal meat (beef, horse, venison or turkey) with vitamin supplementation can satisfy the feed requirements of cheetah (Bechert et al, 2002) but may fail to provide the higher energy requirements of this species compared to other felines (Allan et al, 1995). As a result most captive cheetahs fail to derive their energy requirements that are necessary for normal physiological functions. Owen-Smith and Mills (2008) suggested that cheetah requires on average $2.1 \mathrm{~kg}$ of food a day but variation in food items must be taken in consideration. In the wilderness of Africa cheetahs feed on a variety of prey animals, including impala, kudu, nyala, waterbuck, gazelles, zebra and springbuck to sustain their energy needs which may not be encountered in captivity (Lindsey et al, 2011).
In conclusion, it is recommended to vary food items for captive cheetahs on a daily basis to be able to meet their energy requirements. It is highly recommended to allow the animals to feed on a freshly killed prey (whole carcass) at least once a week to provide them with necessary nutritional elements.

\section{References}

Allan, M.E., Oftedal, O.T., Earle, K.E, Seidensticker, J., Vilarin, L. (1995): Do maintenance energy requirements of felids reflect their feeding strategies?. Nutrition Advisory Group Proc. 1: 97-103.

Barigye, R., Schamber, EV., Newell, T.k., Dyer, N.W. (2007): Hepatic lipidosis and other test findings in two captive adult porcupines ( Erethizon dorsatum) dying from a "sudden death syndrome". J . Vet Diagn Invest 19:712-716.

Bechert, U., Mortenson, J., Dierenfeld, E.S., Cheeke, P., Keller, M., Holick, M., Chen, I.C., Rogers, Q.(2002): Diet composition and blood values of captive cheetah ( A.jubatus) fed either supplemented meat or commercial food preparations. J Zoo.Wildl.Med. 33: 16-28.

Beltran, JF., Delibes,M., Recio, F., Aza, C. (2000): Haematological and serum chemical characteristics of the Iberian lynx (Lynx pardina) in south western Spain. Can.J.Zool.69: 840-846.

Biourge, V., Pion, P., Lewis, J., Morris, J.G. , Rogers, Q.R. 
(1991): Dietary management of idiopathic feline hepatic lipidosis with a liquid diet supplemented with Citrulline and Choline. Jn.Nutri. 121:155-156.

Cebra, CK., Garry,FB., Getz, DM., Fettman, MJ. (1997): Hepatic lipidosis in anorectic, lactating Holeistin cattle. A retrospective study of serum biochemical abnormalities. J Vet.Intern. Med 11: 231-237.

Center, S.A. (2005): Feline hepatic lipidosis. Vet.Clin. Small.Anim. (35): 225-269.

Clum, NJ., Fitzpatrick, MP., Dierenfeld, ES. (1996): Effect of diets on nutritional content of whole vertebrate prey. Zoo Biol. 15: 525537.

Dierenfeld, E.S., Alcorn, H.L., and Jacobsen, K.L. (2001): Nutrient composition of whole vertebrate prey fed in zoos. AZA nutritional advisory group fact sheet. A review. American zoo and aquarium associ. Silver spring, Maryland.

Fagan, D.A. (1980): Diet consistency and periodontal diseases in exotic carnivores. Proc.Conf.Am.Assoc.Zoo.Vet, Washington, DC. 34-37.

Gonzalez, F.D., Muino, R., Pereira,V., Campos, R., Benedito, JL. (2011): Relationship among blood indicators of lipomobilization and hepatic function during early lactation in high yielding dairy cows. J Vet.Sci 12(3):251-255.
Guggisberg, C.A.W. (1975): Wild cats of the world (Ed). Taplinger, New York.

Hoeing, M., Thomaseth, K., Brandao, J., Waldron, M., Ferguson, D.C. (2006): Assessment and mathematical modeling of glucose turnover and insulin sensitivity in lean and obese cats. Domest Anim Endocrinol. 31(4): 373-389.

Hoeing, M., Thomaseth, K., Brandao, J., Waldron, M., Ferguson, D.C. (2007): Fatty acid turnover, substrate oxidation and heat production in lean and obese cats during the euglycemic hyperinsulinemic clamp. Domes Anim endocrinol. 32(4): 329-338.

James, S.B., Raphael, L. , Clippinger,T. (2000): Diagnosis and treatment of liver lipidosis in a Barred owl (Strix varia).J Avi.Med.Surg.14, (4):268-277.

Lindsey, P., Tambling, C.J., Brummer, R., Davies-Mostert, H., Hayward, M., Marnewick, K., Parker, D. (2011): Minimum prey and area requirements of the vulnerable cheetah, Acinonyx jubatus: implications for reintroduction and management of the species in South Africa. Oryx 61: 113.

Marco, I., Martinez, F., Pastor, J, Lavin, S. (2000): Haematological and serum chemistry values of captive European wild cat. Can.J.Wild.Dis. 36: 445-449.

Marker, L.L, Dickman, A.J. (2003): Morphology, physical condition and growth of the cheetah 
( Acinonyx jubatus). J.Mammology. 84(3): 840-850.

Marker-Kraus, L. (1997): History of the cheetahs in zoos. Int. Zoo Year Book. 35: 27-43.

Mussart, N.B., Koza,G.A., Solis,G., Coppo, j.A. (2009): Approval to some haematological variables of healthy captive " yaguarete" ( Panthera onca) from North east Argentine. Rev.Vet 20: 1, 50-53.

National research council (1985): Nutrient requirements of dogs, revised. National Academy press. Washington DC.

National research council (1994): Nutrient requirements of poultry, $9^{\text {th }}$ revised edition. National academy press. Washington DC.

O'Brien, S.J., Rockele, M.E., Marker, L., Newman, L., Wrinkle, C.W.; Meltzer, D., Colly, L., Evermann, J., Bush, M. and Wildt, D.E. (1985): Genetic basis for species vulnerability in the cheetahs. Science 227: 1428-1434.
Owen-Smith, N. , Mills, M.G. (2008): Predator- prey size relationship in an African large mammal food web. J.Anim.Ecol. 77: 163-183.

Palmer, M.V. , Olsen, S.C. (2002): Hepatic lipidosis in pregnant captive American bison (Bison bison). J Vet.Diagn.Invest. 14:512551.

Roelk, ME. (1987). Florida panther biochemical investigation. Final report. Endangered species project E1-11. Florida game and fresh water fish commission, Florida. 178pp.

Saleh, M.A, Helmy, I. , Giegengack, R. (2001): The cheetah, Acinonyx jubatus ( Schreber, 1776). In Egypt. Mammalia 65: 177-194.

Van saun, R.J. (2007): Hepatic lipidosis in Llmas and Alpacas part 1. Recognizing the disease. Lamblink.com, 3(11): 40-42.

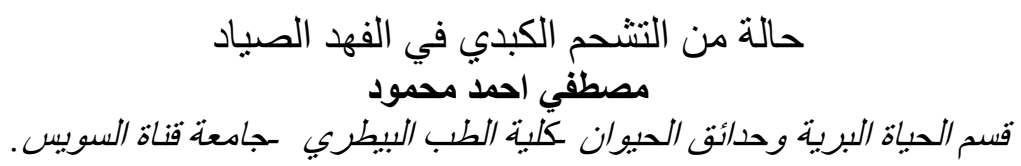

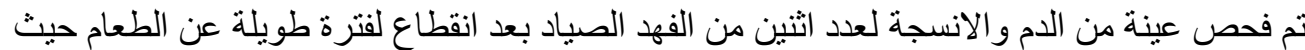

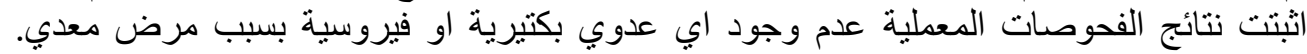

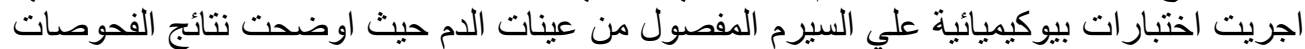

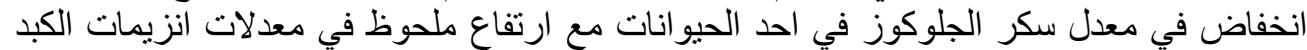

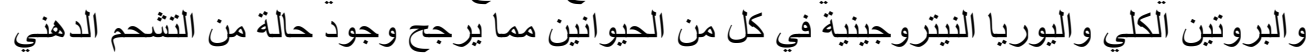

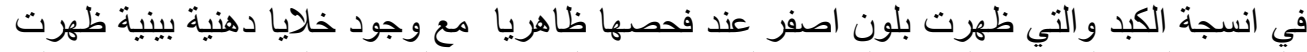

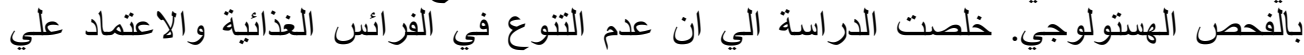

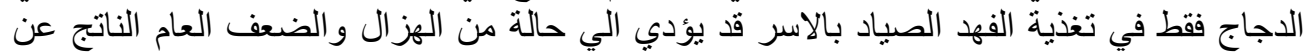

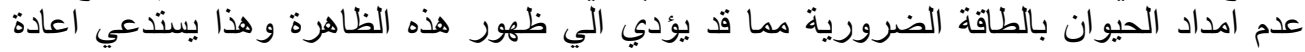
النظر في الجدول الغذائي لتوسيع القاعدة الغذائية لهذه النوع من العائلة النئة القطية. 